Shagufta Perveen*, Ghada Ahmed Fawzy, Areej Mohammad Al-Taweel, Raha Saud Orfali, Hasan Soliman Yusufoglu, Maged Saad Abdel-Kader, Ruba Mahmoud Al-Sabbagh

\title{
Antiulcer Activity of Different Extracts of Anvillea garcinii and Isolation of Two New Secondary Metabolites
}

https://doi.org/10.1515/chem-2018-0037

received January 9, 2018; accepted March 6, 2018.

\begin{abstract}
Anvillea garcinii (AG, Asteraceae) commonly called "nougd" in Arabic is traditionally used for the treatment of different gastrointestinal disorders. This study evaluates the effects of ethanol, chloroform and $n$-butanol extracts of AG on ulcerative colitis induced by various ulcerogens in rats and the isolation of new secondary metabolites. Ethanol extracts of the leaf of the AG demonstrated a powerful anti-ulcer activity which could be attributed to the synergistic effect of its constituents. Therefore, our results would be the first proof of traditional use of AG as an antiulcer ailment.
\end{abstract}

Keywords: Anvillea garcinii; Sesquiterpene glucoside; Flavonoid glycoside; anti-ulcer

\section{Introduction}

Anvillea garcinii (Burm.f.) DC. (Asteraceae) is a shrub found in the deserts of Iran to North Africa, including many Middle Eastern countries including Palestine, Egypt and Saudi Arabia [1]. AG is a famous medicinal

*Corresponding author: Shagufta Perveen, Department of Pharmacognosy, College of Pharmacy, King Saud University. P. O. Box 22452, Riyadh 11495, Kingdom of Saudi Arabia, E-mail: shagufta792000@yahoo.com

Ghada Ahmed Fawzy: Department of Pharmacognosy, Faculty of Pharmacy, Cairo University, Cairo 11562, Egypt

Areej Mohammad Al-Taweel, Raha Saud Orfali, Ruba Mahmoud Al-

Sabbagh: Department of Pharmacognosy, College of Pharmacy, King Saud University. P. O. Box 22452, Riyadh 11495, Kingdom of Saudi Arabia

Hasan Soliman Yusufoglu, Maged Saad Abdel-Kader: Department of Pharmacognosy, College of Pharmacy, Prince Sattam Bin Abdulaziz University, P.O. Box 173, Al-Kharj 11942, Saudi Arabia

Maged Saad Abdel-Kader: Department of Pharmacognosy, Faculty of Pharmacy, Alexandria University, Alexandria 21215, Egypt plant widely used for its medicinal properties for the treatment of many diseases such as dysentery, hepatitis, gastro-intestinal troubles, lung disease, colds, pulmonary affections, digestive problems and liver related diseases. These traditional uses are linked to the numerous biological properties that AG possesses such as anti-HIV, antitumor, hypoglycemic and anti-inflammatory activities [2-6]. Previous phytochemical work on the Saudi AG has confirmed that this plant is a reliable source of flavonoids and sesquiterpenes [7-9]. In continuation of our interest in the isolation of more bioactive constituents from Saudi medicinal plants [10], we selected AG with the aim to investigate more of its biological activities. The present paper describes the isolation of two new compounds, $9 \alpha$-hydroxyparthenolide-9- $O-\beta$-D-glucopyranoside (1), spinacetin 3-O-[ $\alpha$-L-rhamnopyranosyl- $(1 \rightarrow 6)-\beta$ D-glucopyranoside]-7- $O$-[ $\alpha$-L-rhamnopyranoside] and three known flavonoids, namely kaempferol 3-Orutinoside (3), kaempferol 7-O- $\beta$-D-glucopyranoside (4) and quercetin7-O- $\beta$-D-glucopyranoside (5) from the leaves of AG (Figure 1). The total ethanol extract, $n$-butanol and chloroform fractions were tested for antiulcer activity.

\section{Material and methods}

\subsection{General}

The proton, ${ }^{13}$ Carbon NMR and 2D NMR spectra were recorded on a AMX-500 Bruker spectrometer and tetramethylsilane (TMS) was used as a standard. Chemical shifts are given in ppm $(\delta)$ relative to TMS and coupling constants, $J$, are reported in Hz. ESI-MS analyses were measured on an Agilent Triple Quadrupole 6410 QQQ LC/MS mass spectrometer with ESI +/- ion source (gas temperature $350^{\circ} \mathrm{C}$, nebulizer pressure 60 psi and gas flow rate $10 \mathrm{~L} / \mathrm{min}$ ) operating in +/- scan ionization modes through a direct infusion method by using $\mathrm{CH}_{3} \mathrm{OH}$ 


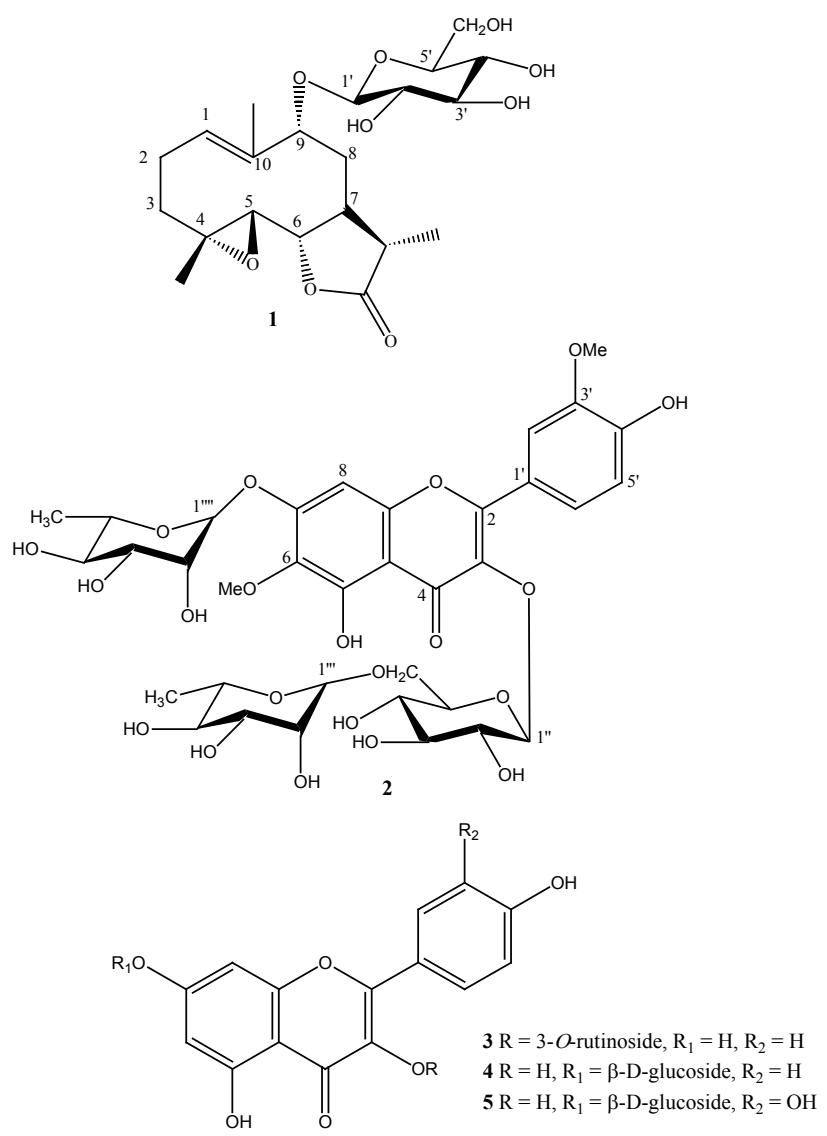

Figure 1: Structures of compounds 1-5.

$/ \mathrm{H}_{2} \mathrm{O}(1: 1 \mathrm{v} / \mathrm{v})$ with a flow rate of $0.3 \mathrm{~mL} / \mathrm{min}$. Column chromatography was carried out on a Sephadex LH-20 (Merck, Darmstadt, Germany). TLC was performed on precoated plates (Silica \& RP-18 $\mathrm{F}_{254}$, Merck, Germany); the detection was performed at 254 and $354 \mathrm{~nm}$ by spraying with ceric sulphate and sulphuric acid reagents.

\subsection{Physical data}

\subsubsection{Compound 1 ( $9 \alpha$-hydroxyparthenolide-9-0- $\beta$-D- glucopyranoside)}

Yellow gummy solid; $[\alpha]^{25} \mathrm{D}=-34.5\left(c=0.16, \mathrm{CH}_{3} \mathrm{OH}\right)$; (-) HRESIMS $m / z$ 427.2034 $[\mathrm{M}+\mathrm{H}]^{+}$(calcd. for $\mathrm{C}_{21} \mathrm{H}_{32} \mathrm{O}_{9}$, 428.2046); ${ }^{1} \mathrm{H} \&{ }^{13} \mathrm{C}$ NMR data see Table 1.

\subsubsection{Compound 2 (Spinacetin 3-0-[ $\alpha-\mathrm{L}-$}

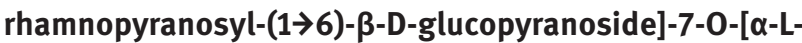
rhamnopyranoside])

Yellow gummy solid; $[\alpha]^{25} \mathrm{D}-42.0$ (c 0.10, $\mathrm{CH}_{3} \mathrm{OH}$ ); (+) HRESIMS $m / z 800.2281[\mathrm{M}+\mathrm{H}]^{+}$(calcd. for $\mathrm{C}_{35} \mathrm{H}_{44} \mathrm{O}_{21}$, 800.2375); ${ }^{1} \mathrm{H} \&{ }^{13} \mathrm{C}$ NMR data see Table 2.
Table 1: ${ }^{1 \mathrm{H}}$ - and ${ }^{13} \mathrm{CNMR}$ data for Compound 1 (DMSO, $J$ in $\mathrm{Hz}, \delta$ in ppm, 500 and $125 \mathrm{MHz}$ ).

\begin{tabular}{|c|c|c|}
\hline & 1 & \\
\hline Position. & $\delta_{H}$ & $\delta_{c}$ \\
\hline 1 & $5.55(\mathrm{~d}, J=11.5)$ & 122.8 \\
\hline $2 \alpha$ & $2.09(\mathrm{dd}, J=10.0,6.0)$ & 23.6 \\
\hline $2 \beta$ & $2.36 \mathrm{~m}$ & \\
\hline $3 \alpha$ & $1.08 \mathrm{~m}$ & 36.7 \\
\hline $3 \beta$ & $2.03(\mathrm{~d}, J=10.0)$ & \\
\hline 4 & - & 61.4 \\
\hline 5 & $2.80(\mathrm{~d}, J=9.0)$ & 65.5 \\
\hline 6 & $3.97(\mathrm{t}, J=9.5)$ & 81.6 \\
\hline 7 & $3.13 \mathrm{~m}$ & 49.0 \\
\hline $8 \alpha$ & $1.81(\mathrm{dd}, J=9.5,15.0)$ & 31.3 \\
\hline $8 \beta$ & $2.16(\mathrm{dd}, J=5.5,15.0)$ & \\
\hline 9 & $4.19 \mathrm{brs}$ & 74.4 \\
\hline 10 & - & 134.4 \\
\hline 11 & $2.39 \mathrm{~m}$ & 41.8 \\
\hline 12 & - & 178.3 \\
\hline 13 & $1.08(\mathrm{~d}, J=5.0)$ & 13.2 \\
\hline 14 & $1.63 \mathrm{~s}$ & 16.3 \\
\hline 15 & $1.23 \mathrm{~s}$ & 17.3 \\
\hline $1^{\prime}$ & $4.23(\mathrm{~d}, J=7.5)$ & 99.3 \\
\hline $2^{\prime}$ & $3.03 \mathrm{~m}$ & 74.2 \\
\hline $3^{\prime}$ & $3.11 \mathrm{~m}$ & 76.8 \\
\hline $4^{\prime}$ & $3.07 \mathrm{~m}$ & 70.5 \\
\hline $5^{\prime}$ & $3.08 \mathrm{~m}$ & 77.4 \\
\hline $6{ }^{\prime} \mathrm{a}$ & $3.64(\mathrm{dd}, J=6.0,10.0)$ & 61.6 \\
\hline $6{ }^{\prime} b$ & $3.42(\mathrm{dd}, 5.5,10.0)$ & \\
\hline
\end{tabular}

\section{Biological activities}

\subsection{Anti-ulcer activity}

\subsubsection{Animals}

Sprague-Dawley albino rats (male, 120-150 g), acquired from the Experimental Animal Center, College of Pharmacy, King Saud University (KSU), were used in the study. The animal care and ethical committee of the Pharmacy college, KSU approved all of the experimental protocols with clearance \# 426.

Animals were kept under standard conditions (12 hour light \& 12 hour dark cycle) with controlled temperature and humidity. They were fed rat pellet diet (standard) with constant access to the tap water ad libitum for one whole week for acclimatization. Before any treatment, rats 
Table 2: ${ }^{1} \mathrm{H}$ - and ${ }^{13} \mathrm{CNMR}$ data for Compound 2 (DMSO, $J$ in $\mathrm{Hz}, \delta$ in ppm, 500 and $125 \mathrm{MHz}$ ).

\begin{tabular}{|c|c|c|}
\hline & 2 & \\
\hline Position. & $\delta_{\mathrm{H}}$ & $\delta_{c}$ \\
\hline 2 & - & 147.2 \\
\hline 3 & - & 133.3 \\
\hline 4 & - & 179.7 \\
\hline 5 & - & 151.8 \\
\hline 6 & - & 131.4 \\
\hline 7 & - & 152.6 \\
\hline 8 & $6.52(\mathrm{~s})$ & 94.6 \\
\hline 9 & - & 157.7 \\
\hline 10 & - & 104.5 \\
\hline $1^{\prime}$ & - & 123.0 \\
\hline $2^{\prime}$ & $7.52(\mathrm{~s})$ & 115.8 \\
\hline $3^{\prime}$ & - & 150.7 \\
\hline $4^{\prime}$ & - & 146.4 \\
\hline $5^{\prime}$ & $7.01(\mathrm{~d}, J=5.0)$ & 111.8 \\
\hline $6^{\prime}$ & $7.79(\mathrm{~d}, J=5.0)$ & 122.0 \\
\hline 6-OMe & $3.76(\mathrm{~s})$ & 60.8 \\
\hline $3^{\prime}-\mathrm{OMe}$ & $3.86(\mathrm{~s})$ & 56.2 \\
\hline $1^{\prime \prime}$ & $5.41(\mathrm{~d}, J=5.0)$ & 99.3 \\
\hline $2^{\prime \prime}$ & $3.05(\mathrm{~m})$ & 77.7 \\
\hline $3^{\prime \prime}$ & $3.96(\mathrm{~d}, J=10.0)$ & 76.9 \\
\hline $4^{\prime \prime}$ & $3.40-4.0(\mathrm{~m})$ & 70.5 \\
\hline $5^{\prime \prime}$ & $3.75(\mathrm{~m})$ & 75.8 \\
\hline 6"a & $3.48(\mathrm{~m})$ & 63.4 \\
\hline $6^{\prime \prime b}$ & $3.54(\mathrm{~m})$ & \\
\hline $1^{\prime \prime \prime}$ & $4.64(\mathrm{~s})$ & 101.3 \\
\hline $2^{\prime \prime \prime}$ & $3.40-4.0(\mathrm{~m})$ & 70.7 \\
\hline $3^{\prime \prime \prime}$ & $3.40-4.0(\mathrm{~m})$ & 69.3 \\
\hline $4^{\prime \prime \prime}$ & $3.40-4.0(\mathrm{~m})$ & 71.5 \\
\hline $5^{\prime \prime \prime}$ & $3.40-4.0(\mathrm{~m})$ & 68.5 \\
\hline $6^{\prime \prime \prime}$ & $1.13(\mathrm{~d}, J=5.0)$ & 15.1 \\
\hline $1^{\prime \prime \prime \prime}$ & $4.10(\mathrm{~s})$ & 103.2 \\
\hline $2^{\prime \prime \prime \prime}$ & $3.40-4.0(\mathrm{~m})$ & 70.7 \\
\hline $3^{\prime \prime \prime \prime}$ & $3.40-4.0(\mathrm{~m})$ & 70.5 \\
\hline $4^{\prime \prime \prime \prime \prime}$ & $3.40-4.0(\mathrm{~m})$ & 71.0 \\
\hline $5^{\prime \prime \prime \prime}$ & $3.40-4.0(\mathrm{~m})$ & 68.8 \\
\hline $6^{\prime \prime \prime \prime}$ & $1.03(\mathrm{~d}, J=5.0)$ & 16.5 \\
\hline
\end{tabular}

were made to fast overnight and then divided into eight different groups (6 rats in each group). Group I was the control group. Group II was administered Ranitidine at a dose of $50 \mathrm{mg} / \mathrm{kg}$ p.o. Groups III-VIII were treated with two different doses; 200 and $400 \mathrm{mg} / \mathrm{kg}$ of each of the ethanol extract, chloroform and $n$-butanol fractions of AG leaves orally in the anti-ulcer study and IP (intraperitoneally) for the gastric secretion evaluation.

\subsubsection{Pylorus-ligated rats}

Fasting was maintained for 36 hours under ether anesthesia before pylorus ligation. AG extracts were administered IP (intraperitoneally) immediately after pylorus ligation and the rats were sacrificed 6 hours after pylorus ligation. Their stomachs were taken and contents were collected, the volumes were measured and centrifuged and then evaluated for titratable acidity at $\mathrm{pH} 7$ against $0.01 \mathrm{~mol} / \mathrm{L}$ $\mathrm{NaOH}$ [11].

\subsubsection{Gastric lesions induced by various ulcerogens}

AG test extracts were given 30 min before the administration of the ulcerogens. Each rat was administered one $\mathrm{mL}$ of ulcerogen $(80 \% \mathrm{EtOH}, 25 \% \mathrm{NaCl}$ or $0.2 \mathrm{~mol} / \mathrm{L} \mathrm{NaOH})$. The rats were sacrificed after 24 hours and the stomachs were opened along the greater curvature. It was inspected for lesions and scoring in the stomach after washing with saline, the method published by Robert et al. [12].

\subsubsection{Gastric lesions induced by indomethacin}

The three extracts of AG were given to rats $30 \mathrm{~min}$ before administration of indomethacin at two doses of 200 and $400 \mathrm{mg} / \mathrm{kg}$. Indomethacin $(30 \mathrm{mg} / \mathrm{kg})$ was orally administered to the $36 \mathrm{~h}$ fasted rats. The animals were sacrificed 6 hour after indomethacin treatment, and then the stomachs were removed, washed with normal saline solution, and then examined for ulceration [13].

\subsubsection{Ulcers induced by hypothermic restraint stress}

Animals were fasted (36 hour), with access to water. The two doses of AG extracts were orally administered to the rats. After thirty minutes the rats were relocated to cages and placed inside a refrigerator kept at $3 \pm 1^{\circ} \mathrm{C}$ for 3 hours. Then the animals were sacrificed and their stomachs 
were removed and examined for severity of intraluminal bleeding and ulceration according to the previously published method [14].

\subsubsection{Gastric wall mucus (GWM) estimation}

GWM was estimated according to a modified procedure published by Corne et al. [15]. The glandular part of the stomach was completely separated from the rumen, weighed, and transferred to $10 \mathrm{~mL}$ of $0.1 \% \mathrm{w} / \mathrm{v}$ Alcian blue solution. Tissue of the segment was stained for 2 hour in Alcian blue, initially after $15 \mathrm{~min}$, then after $45 \mathrm{~min}$. The dye complexed gastric wall mucus was then extracted with 10 $\mathrm{mL}$ of $0.5 \mathrm{mmol} / \mathrm{L} \mathrm{MgCl}_{2}$. The resulting emulsion material was centrifuged for $10 \mathrm{~min}$ at $4000 \mathrm{rpm}$ and absorbance of the aqueous layer was measured at $580 \mathrm{~nm}$ at room temperature. The quantity of Alcian blue was calculated after the extraction of per gram wet glandular tissue.

\subsubsection{Determination of reduced glutathione}

The glandular part of the stomach was homogenized at room temperature and centrifuged at $3000 \mathrm{rpm} .2 \mathrm{~mL}$ of supernatant was mixed with $4 \mathrm{~mL}$ of $0.4 \mathrm{~mol} / \mathrm{L}$ Tris buffer at $\mathrm{pH}$ 8.9. $0.1 \mathrm{~mL}$ of 5,5'-dithio-bis(2-nitrobenzoic acid) was added and the absorbance was measured at $412 \mathrm{~nm}$, within 5 min [16].

\subsubsection{Determination of malondialdehyde (MDA)}

Animals were sacrificed after 1 hour of ethanol administration. The stomachs were removed, washed, homogenized, and $1.25 \mathrm{~mL}$ of $20 \%$ trichloroaceticacid (TCA) was mixed with $250 \mu \mathrm{L}$ of the stomach homogenate. The mixture was heated in a boiling water bath for $30 \mathrm{~min}$ and then cooled at $4^{\circ} \mathrm{C}$ and centrifuged for 10 minutes. The absorbance of developed pink-colored material was measured at $535 \mathrm{~nm}$. MDA concentration was expressed as $\mathrm{nmol} / \mathrm{g}$ of tissue.

\subsubsection{Histopathological study}

Small pieces of stomachs were fixed by $0.1 \mathrm{M}$ phosphate buffer ( $\mathrm{pH} 7.4$ ), 4\% neutral buffer formalin, embedded into paraffin, sectioned for $5-6 \mu \mathrm{m}$ pieces, and then mounted on glass microscope slides by histopathological techniques. The sections were stained with Hematoxylene \& Eosin stain and examined by microscope [17]. The slides were then examined by microscope for pathomorphological changes such as hemorrhage, edema, congestion and erosions using an arbitrary scale for severity assessments of these changes.

\subsubsection{Statistical analysis}

Tables and figure values are given as mean \pm SEM. The data was analyzed using a Student's t test followed by a oneway analysis of variance (ANOVA) to compare individual data sets.

\section{Results and discussion}

\subsection{Structure elucidation of new compounds 1 and 2}

Chromatographic isolation of chloroform and $n$-butanol fractions of the total ethanol extract of AG by silica gel and LH-20 Sephadex columns, yielded two new (1 \& 2) and three known compounds (3-5) (Figure 1). The structures of the compounds were conducted by spectral analysis, including ESI-MS and 1D, 2D NMR.

Compound 1 was obtained as a yellowish gummy solid. The Carbon NMR spectrum revealed twenty-one carbons, including three methyl, four methylene, eleven methine and three quaternary carbons. The proton NMR spectrum showed the singlets of two methyl at $\delta \mathrm{H} 1.23$ $(3 \mathrm{H}, \mathrm{s})$ and $1.63(3 \mathrm{H}, \mathrm{s})$, doublet of one methyl at $\delta \mathrm{H} 1.16$ $(3 \mathrm{H}, \mathrm{d}, J=6.5 \mathrm{~Hz})$ and an olefinic proton at $\delta \mathrm{H} 5.55(1 \mathrm{H}$, $\mathrm{d}, J=11.5 \mathrm{~Hz}$ ). The proton NMR spectrum further showed three hydroxy methine protons signals at $\delta \mathrm{H} 2.80(1 \mathrm{H}, \mathrm{d}$, $J=9.0 \mathrm{~Hz}), \delta \mathrm{H} 3.97(1 \mathrm{H}, 5, J=9.5 \mathrm{~Hz})$ and $\delta \mathrm{H} 4.19(1 \mathrm{H}, \mathrm{brs})$ (Table 1). The proton and Carbon NMR spectrum of 1 was closely similar to the $9 \alpha$-hydroxyparthenolide [6], except for the presence of a sugar moiety. The signal of the sugar unit appeared at $\delta_{C} 99.36,74.2,76.8,70.5,77.4$ and 61.6 in the Carbon NMR spectra. The proton NMR spectrum gave a signal for a sugar anomeric proton at $\delta_{\mathrm{H}} 4.23(\mathrm{~d}$, $J=7.5 \mathrm{~Hz}$ ). This suggests that the sugar unit adopts a $\beta$ configuration. The acid hydrolysis process of $\mathbf{1}$ afforded the D-glucose sugar which was identified through Co-TLC and from the sign of its optical rotation. In the case of the $9 \alpha$-hydroxy group, the C-9 carbon atom usually appears in the range of $\delta_{\mathrm{C}} 70-72 \mathrm{ppm}$. However, in compound $\mathbf{1}$, it gave a signal at $\delta_{\mathrm{C}} 74.4$, showing the glycosylation is at C-9 position. The other signals of $\mathbf{1}$ showed complete 
agreement to the compounds reported earlier [6]. The location of the D-glucose sugar was confirmed by long range $\mathrm{HMBC}$ experiments in which $\mathrm{H}-\mathrm{1}^{\prime}\left(\delta_{\mathrm{H}} 4.23\right)$ showed $^{3} \mathrm{~J}$ correlation with $C-9\left(\delta_{C} 74.4\right)$. The individual signal of the glucose unit was identified by ${ }^{1} \mathrm{H}-{ }^{1} \mathrm{H}$ COSY correlations, starting from the anomeric proton at $\delta_{\mathrm{H}} 4.23$ and further corroborated through HMBC correlations. Finally, metabolite 1 was identified as $9 \alpha$-hydroxyparthenolide-9$O$ - $\beta$-D-glucopyranoside.

Compound $\mathbf{2}$ was obtained as a yellow gummy material. The proton NMR spectrum of $\mathbf{2}$ showed prominent signals at $\delta_{\mathrm{H}} 6.52(\mathrm{H}-8, \mathrm{~s}), 7.52\left(\mathrm{H}-2^{\prime}, \mathrm{s}\right), 7.01$ $\left(\mathrm{H}-5^{\prime}, \mathrm{d}, J=5.1 \mathrm{~Hz}\right)$ and $7.79\left(\mathrm{H}-6^{\prime}, \mathrm{d}, J=5.0 \mathrm{~Hz}\right)$. These aromatic protons showed direct correlations in HSQC spectrum with carbons at $\delta_{\mathrm{C}} 94.6(\mathrm{C}-8), 115.8\left(\mathrm{C}-2^{\prime}\right), 111.8$ $\left(\mathrm{C}-5^{\prime}\right)$ and 122.0 (C-6'), respectively, indicating a 3, 5, 6, 7, 3', 4' hexasubstituted flavonol skeleton (Table 2). The HMBC correlations of the methoxy proton signal at $\delta_{\mathrm{H}}$ 3.76 with the carbon at $\delta_{\mathrm{C}} 131.4$ and $\delta_{\mathrm{H}} 3.86$ with carbon at $\delta_{C} 150.7$ indicated the presence of two methoxy groups at C-6 and C-3', respectively. Thus, the aglycone part is 6,3'-dimethoxy-3,5,7,4'-tetrahydroxyflavonol (Spinacetin) [18]. The ${ }^{1} \mathrm{H}$ proton and ${ }^{13}$ Carbon NMR spectra showed signals of three anomeric protons and carbon atoms, which suggested that compound $\mathbf{2}$ is a flavonol trisaccharide. The H-C HSQC 2D spectrum showed the correlation of sugar anomeric proton at $\delta_{\mathrm{H}} 5.41(\mathrm{~d}, J$ $\left.=5.0 \mathrm{~Hz}, \mathrm{H}-1^{\prime \prime}\right)$ with $\delta_{\mathrm{C}} 102.1 ; \delta_{\mathrm{H}} 4.64$ (brs, $\left.\mathrm{H}-1^{\prime \prime \prime}\right)$ with $\delta_{\mathrm{C}}$ 101.3; and at $\delta_{\mathrm{H}} 4.10$ (brs, $\left.\mathrm{H}-1^{\prime \prime \prime \prime}\right)$ with $\delta_{\mathrm{C}}$ 103.2. Complete assignment of protons and carbons of the sugar moieties was achieved by COSY, HMBC and HSQC spectral analysis. These sugars were glucose and two rhamnose moieties, characterized by two secondary methyl groups. The ESI-MS spectra showed signals at $m / z 509$, resulting from the loss of both rhamnose moieties and it further gave peaks at $m / z 347$ for the flavonol spinacetin. The attachment point of sugar moieties on the flavonol was identified by the proton and Carbon ${ }^{3} \mathrm{HMBC}$ correlations of $\delta_{\mathrm{H}} 5.41$ (Glc H-1") to $\delta_{\mathrm{C}} 133.0$ (C-3) and $\delta_{\mathrm{H}} 4.10$ (RhaII $\left.\mathrm{H}-1^{\prime \prime \prime}\right)$ to $\delta_{\mathrm{C}} 152.6(\mathrm{C}-7)$. Anomeric protons of RhaI at $\delta_{\mathrm{H}}$ 4.64 (H-1") showed strong ${ }^{3} \mathrm{~J}$ HMBC correlations with the sugar oxymethylene carbon at $\delta_{C} 63.4$ (glucoseC-6") indicating the inter glycoside linkage between rhamnose and glucose sugars and it was further confirmed by the low frequency shift of the glucose oxymethylene carbon. The individual signals of sugar units were identified through $\operatorname{COSY}{ }^{1} \mathrm{H}-{ }^{1} \mathrm{H}$ Shift of anomeric protons at $\delta_{\mathrm{H}}$ 5.41, 4.64 and 4.10 and further corroborated with HMBC correlations. The de-shielded sugar oxymethylene protons at $\delta_{\mathrm{H}} 3.48$ and 3.54 and carbon at $\delta_{\mathrm{c}} 63.4$ of the glucose moiety compared without attachment of rhamnose sugar, confirmed the presence of rhamnose moiety at C-6 position of the glucose sugar. Upon acid hydrolysis, it yielded L-rhamnose and D-glucose, which was confirmed by its positive optical rotation sign and through co-TLC with the standards. Furthermore, HMQC, HMBC and COSY correlations were in full agreement with the assigned structure of compound $\mathbf{2}$ as spinacetin 3-O-[ $\alpha$-L-rhamnopyranosyl-( $1 \rightarrow 6)-\beta$-D-glucopyranoside]7-O-[ $\alpha$-L-rhamnopyranoside].

Compounds 3-5 were identified as kaempferol 3-Orutinoside (3) [19], kaempferol 7-O- $\beta$-D-glucopyranoside (4) [20] and quercetin7-O- $\beta$-D-glucopyranosid (5) [21] by comparing NMR with published literature.

\subsection{Anti-ulcer activity}

From the results presented in table S1, it is deduced that all AG extracts demonstrated a significant decrease in gastric secretion and titratable acidity, in gastric lesion index in pylorus rats, except for the chloroform fraction which exhibited the weakest effect. Concerning the antiulcer effect of the extracts against the different ulcerating agents, AG total ethanol extract lessened the ulcer index induced by ethanol, and it was followed by the AG $n$-butanol fraction (Table S2). Only the AG total ethanol extract and $n$-butanol fraction decreased the ulcer index induced by either sodium chloride or sodium hydroxide. Data in table S2, show that the AG total ethanol extract $(400 \mathrm{mg} / \mathrm{kg}$ ) possessed the most pronounced anti-ulcer effect. As for the ulcer index induced by indomethacin, AG, $n$-butanol fraction and ethanol extracts, at doses of $400 \mathrm{mg} / \mathrm{kg}$, exhibited a significant decline in ulcer index induced by indomethacin, while the chloroform fraction was ineffective towards reducing ulcer index in this concern (Table S3).

Data shown in table S4 confirmed that both the intraluminal bleeding score and gastric lesion ulcer index were significantly lessened by the administration of $\mathrm{AG}$ total ethanol extracts (at the two doses), and the high dose of AG chloroform and $n$-butanol fractions ( $400 \mathrm{mg} /$ $\mathrm{kg})$. Ethanol, as an ulcerating agent, reduced the gastric wall mucus in the stomach tissue compared to the normal control (Table S5). Treatment with AG total ethanol extract, both at the two doses, and the high dose of the $n$-butanol fraction demonstrated the most significant improvement in gastric wall mucus. Additionally, ethanol caused significant enhancement in MDA level and reduction in protein levels and glutathione. The AG total ethanol extract, at both doses, and the high dose of the $n$-butanol fraction exhibited a highly significant decline in MDA and 
an increase in total protein levels, while only the AG total ethanol extract at the high dose $(400 \mathrm{mg} / \mathrm{kg})$ appeared to up-regulate glutathione levels (Figures 2,3,4).

The histopathological examination using $\mathrm{H} \& \mathrm{E}$ showed necrosis and EtOH-induced gastric mucosal congestion. Pre-treatment of rats with AG total ethanol $400 \mathrm{mg} / \mathrm{kg}$, and $n$-butanol fraction, at two doses, reduced the congestion and necrosis induced by ethanol (Figure 5).

Gastric mucosa is usually exposed to harmful agents that may induce gastric ulcers, such as pepsin, acid, drugs, food material and bacterial components (Helicobacter pylori). Gastric ulcer is a multifactorial ailment which is challenging to treat because of limited drug efficacy and unwanted side effects. Many medicinal plants and dietary nutrients exhibit gastro-protective activities [22].

Our anti-ulcer study proved the ability of AG total ethanol extract and $n$-butanol fraction to cause a decline in the lesions in pylorus-ligated and titratable acidity in rats. This is in addition to their cytoprotective effect as well as significant anti-secretory activity. They also exhibited a significant dose dependent gastric mucosal protection in ulcers induced by ethanol, sodium chloride and sodium hydroxide. Ethanol-induced gastric ulcers are associated with excessive creation of superoxide anions and hydroperoxy free radicals, thus elevating lipid peroxide production which harms cells and injures cell membranes [23].

Recently, flavonoids have been among the most widely investigated natural compounds for their antiulcer potential. They demonstrate certain gastroprotective pharmacological actions, which act as anti-secretory, cytoprotective and antioxidant agents. They significantly decreased the severity of ulceration caused by pylorus ligation, indomethacin and restraint in rats. Moreover, these compounds demonstrated pronounced antisecretory activity in pylorus ligated rats. The cytoprotective effect of AG total ethanol and $n$-butanol extracts may be due to their abilities to reduce acid secretion and augment the mucosal defensive factors, as well as to inhibit lipid peroxide liberation. Gastric mucosal lipid peroxidation products increase with stomach injury in cold restraintstressed rats [24]. AG total ethanol and $n$-butanol extracts demonstrated a protecting effect on cold restraint-stress possibly by their antioxidant activities. AG total ethanol extract produced a dose dependent increase in GSH (Figure 3), a marked decline in lipid peroxide level and effected mucosal protection. The antioxidant activity of the AG total ethanol extract and the $n$-butanol fraction may be attributed to their flavonoid constituents. The significant anti-ulcer activity of total ethanol extract could be due to the synergism of the chemical constituents

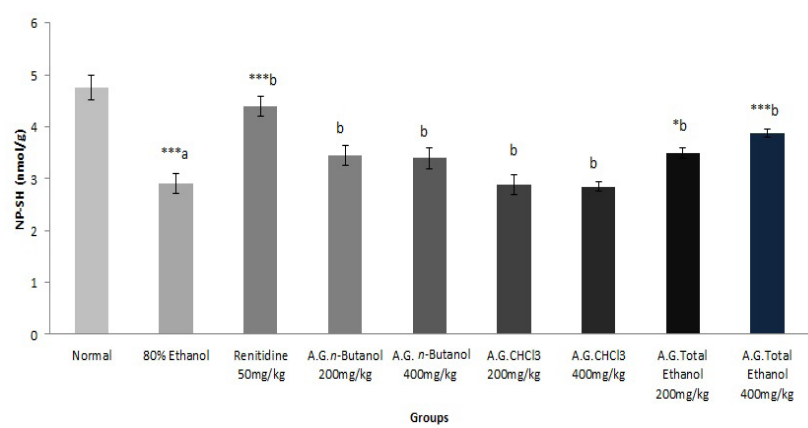

${ }^{\star} p<0.05,{ }^{\star \star \star} p<0.001$ versus control ( $80 \%$ ethanol only) group, Student's t-test, (a) as compared to the control group and (b) as compared to the $80 \%$ ethanol only group.

Figure 2: Effect of AG extracts on GSH concentration in gastric ulcer induced by $80 \%$ ethanol.

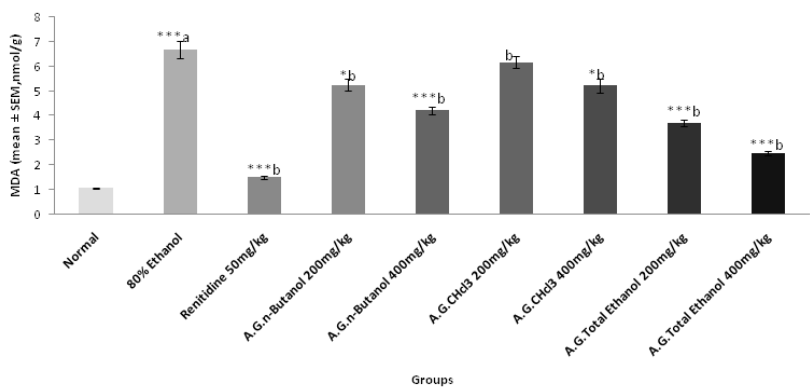

${ }^{\star} p<0.05,{ }^{* *} p<0.001$ versus control ( $80 \%$ ethanol only) group, Student's $t$-test, (a) as compared to the control group and (b) as compared to the $80 \%$ ethanol only group.

Figure 3: Effect of AG extracts on MDA concentration in gastric ulcer induced by $80 \%$ ethanol.

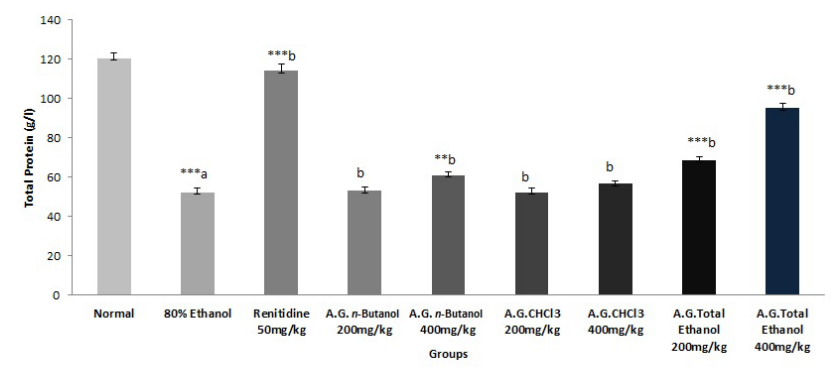

${ }^{*} p<0.01,{ }^{* *} p<0.001$ versus control ( $80 \%$ ethanol only) group, Student's $t$-test, (a) as compared to the control group and (b) as compared to the $80 \%$ ethanol only group.

Figure 4: Effect of AG extracts on total protein in gastric ulcer induced by $80 \%$ ethanol.

such as sesquiterpenes, its amino acids derivatives and flavonoids [25]. The role of flavonoids quercetin, kaempferol, naringin and rutin for anti-ulcer activity are well documented and these can be a cause of strong antiulcer activity [26]. 

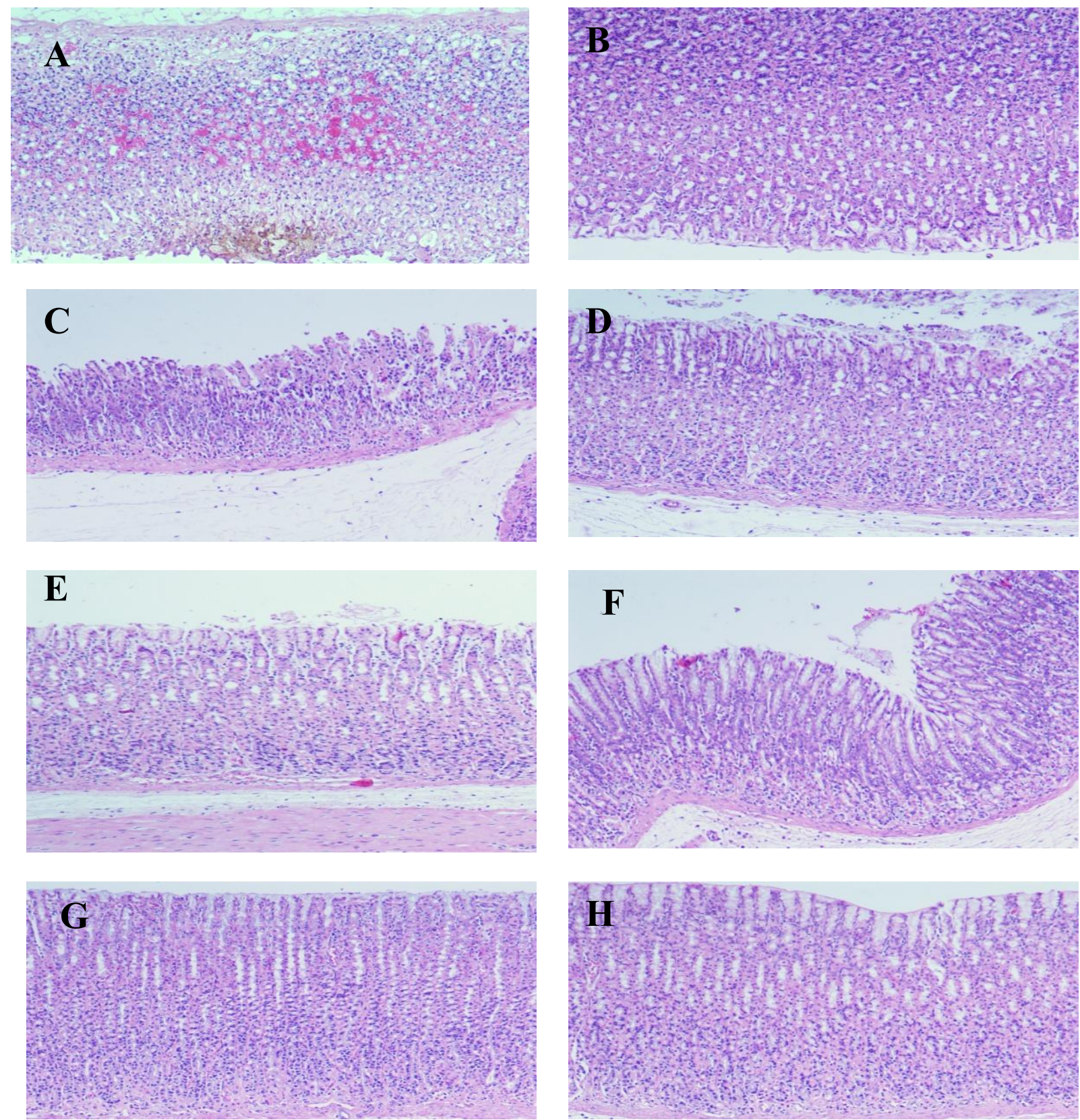

Figure 5: Light micrographs illustrating the effect of AG extracts on ethanol-induced gastric lesions in rats. A: Ethanol-induced gastric mucosal necrosis and congestion; B: Pretreatment of rats with Ranitidine, $50 \mathrm{mg} / \mathrm{kg}$; C: Pretreatment of rats with AG total EtOH, $200 \mathrm{mg} / \mathrm{kg}$; D: Pretreatment with AG total EtOH, $400 \mathrm{mg} / \mathrm{kg}$; E: Pretreatment with $\mathrm{AG} \mathrm{CHCl}_{3}, 200 \mathrm{mg} / \mathrm{kg}$; F: Pretreatment with AG $\mathrm{CHCl}_{3}, 400 \mathrm{mg} / \mathrm{kg}$; G: Pretreatment with AG $n$-butanol, $200 \mathrm{mg} / \mathrm{kg}$; H: Pretreatment with AG $n$-butanol, $400 \mathrm{mg} / \mathrm{kg}$.

Our findings are in agreement with literature, as a recent study shows the dose dependent reduction in gastric mucosal damage by flavonols like kaempferol, quercetin and rutin [27].One of the most investigated flavonoids is quercetin. It protects the gastrointestinal mucosa against necrotic agents, like pylorus-ligation, indomethacin, and gastric ulcers induce by ethanol. This gastroprotective act involves its antioxidant properties [28,29].

\section{Conclusions}

In conclusion, the present study demonstrated the isolation of one new sesquiterpene lactone glucoside and one new flavonoid triglycoside from the leaves of the AG plant through the $n$-butanol fraction. This is the first report to isolate this particular type of sesquiterpene glycoside from plants. AG total ethanol extract demonstrated 
the highest protection for the gastrointestinal mucosa from lesions induced by many ulcerating agents. Different mechanisms of action might be involved in this protective effect, including cytoprotective effects and an anti-secretory mechanism, which enhances the flow of mucosal blood. However, the important mechanism of action which is responsible for the strong anti-ulcer activity of AG total ethanol extract is the antioxidant properties of its constituents, which involves free radical scavenging, inhibition of oxidizing enzymes, as well as reduction of lipid peroxidation [30]. These findings exhibit the preventive effect of ethanol extracts of $A G$ against ulcerative colitis in Wistar rats induced by various ulcerogens in rats. These effects could be attributed due to the anti-inflammatory and antioxidant potential of bioactive constituents present in the extract.

Conflict of interest: The authors declare they have no conflicts of interest.

Acknowledgements: This research project was supported by a grant from the "Research Center of the Female Scientific and Medical Colleges", Deanship of Scientific Research, King Saud University.

\section{References}

[1] Chaudhary S,A., Flora of the Kingdom of Saudi Arabia, Volume. II, Ministry of Agri. \& Water, Riyadh, Saudi Arabia, 2000.

[2] Ghrabi Z., A guide to medicinal plants in North Africa. Malaga, Spain: IUCN Center for Mediterranean Cooperation, 2005, pp. 35.

[3] Kharjul M., Gali V., Kharjul A., Antidiabetic potential of ethanolic extracts of Citrus maxima fruit peel and Anvillea garcinii. I. J. P. I., 2014, 4, 8-18.

[4] Essam A.S., Ahmed M.G., Gaber S.M., Antitumor Germacranolides from Anvillea garcinii. J. Nat. Prod., 1996, 59, 403-405.

[5] Hanane B., Margarita H., Viviana M., Dalila B., Jamel B., JeanClaude M., Anvillea garcinii extract inhibits the oxidative burst of primary human neutrophils. BMC Compl. Alter. Med., 2016, $16,1-10$

[6] [6] $9 \alpha$-hydroxyparthenolide, a novel antitumor sesquiterpene lactone from Anvillea garcinii (Burm.) DC. Experientia. 37:441442. Ulubelen A, Mabry TJ, Aynehchi Y. 1979. Flavonoids of Anvillea garcinii. J. Nat. Prod., 1981, 42, 624-626.

[7] Rustaiyan A., Dabiri M., Jakupovic J., Germacranolides from Anvillea garcinii. Phytochemistry, 1986, 25, 1229-1230.

[8] Hassany B., Hanbali F., Akssira M., Mellouki F., Haidour A., Barrero A.F., Germacranolides from Anvillea radiata. Fitoterapia, 2004, 75, 573-576.

[9] Emilie D., Meryem A.B., Sandrine Z., Mohamed A., Lhoucine R., Claire E., Centrifugal partition chromatography elution gradient for isolation of sesquiterpene lactones and flavonoids from Anvillea radiata. J. Chromat. B., 2015, 985, 29-37.

[10] Areej M.A., Shagufta P., Ghada A.F., Saleh I.A., Kamal E.H.T. New flavane gallates isolated from the leaves of Plicosepalus curviflorus and their hypoglycemic activity. Fitoterapia, 2012, 83, 1610-1615.

[11] Shay H., A simple method for the uniform production of gastric ulceration in the rat. Gastroenterology, 1945, 5, 43-61.

[12] Robert A., Nezamis J.E., Lancaster C., Davis J.P., Field S.O., Hanchar A.J., Mild irritants prevent gastric necrosis through adaptive cytoprotection mediated by prostaglandins. Am. J. Physiol., 1983, 245, G113-G121.

[13] Bhargava K.P., Gupta M.B., Tangri K.K., Mechanism of ulcerogenic activity of indomethacin and oxyphenbutazone. Europ. J. Pharmacol., 1973, 22, 191-195.

[14] Chiu P.J.S., Gerhart C., Brown A.D., Barnett A., Effects of a gastric anti secretory cytoprotectant 2-methyl-8(phenylmethoxy) imidazo (1,2 a)-pyridine-3-acetonitrile (Sch 28080) on cysteamine, reserpine and stress ulcers in rats. Arzneimittel. Forschung., 1984, 34, 783-786.

[15] Corne S.J., Morrissey S.M., Woods R.J., Proceedings: A method for the quantitative estimation of gastric barrier mucus. J. Physiol., 1974, 242, 116P-117P.

[16] Sedlak J., Lindsay R.H., Estimation of total, protein-bound, and nonprotein sulfhydryl groups in tissue with Ellman's reagent. Anal. Biochem., 1968, 25, 192-205.

[17] Culling C.F.A., Handbook of histopathological and histochemical techniques. 3rd Edition, London: Butterwirth and Co, 1974.

[18] Federico, F., Marisol, C., Francisco, A.T., Acylated flavonol glycosides from spinach leaves (Spinacia oleracea), Phytochemistry, 1997, 45, 1701-1705

[19] Leong C.N.A., Tako M., Hanashiro I., Tamaki H., Antioxidant flavonoid glycosides from the leaves of Ficus pumila L. Food Chem., 2008, 109, 415-420.

[20] Wen X., Jianwen L., Changlong L., He-Zhen,W., Yan-Wen L., Kaempferol-7-O- $\beta$-D-glucoside (KG) isolated from Smilax china $\mathrm{L}$. rhizome induces $\mathrm{G} 2 / \mathrm{M}$ phase arrest and apoptosis on HeLa cells in a p53-independent manner. Can Lett., 2008, 264, 229-240.

[21] Legault J., Perron T., Mshvildadze V., Girard-Lalancette K., Perron S., Laprise C., Sirois P., Pichette A., Antioxidant and anti-inflammatory activities of quercetin 7-O- $\beta$-Dglucopyranoside from the leaves of Brasenia schreberi. J. Med. Food., 2011, 14, 1127-34.

[22] Gadekar R., Singour P.K., Chaurasiya P.K., Pawar R.S., Patil U.K., A potential of some medicinal plants as an antiulcer agent. Pharmacog. Rev., 2010, 4, 136-146.

[23] Khazaei M., Salehi H., Protective effect of Falcaria vulgaris extract on ethanol induced gastric ulcer in rat. Iran. J. Pharmacol. Therap., 2006, 5, 43-46.

[24] Bandyopadhyay U., Das D., Bandyopadhyay D., Bhattacharjee M., Banerjee R.K., Role of reactive oxygen species in mercaptomethlimidazole-induced gastric acid secretion and stress induced gastric ulceration. Curr. Sci., 1999, 76, 55-63.

[25] Shagufta P., Areej M.T., Hasan S.Y., Ghada A.F., Ahmed F., Maged S.A., Hepatoprotective and cytotoxic activities of Anvillea garcinii and isolation of four new secondary metabolites. J. Nat. Med., 2018, 72, 106-117. 
[26] Izzo A.A., Carlo G. D., Mascolo N., Capasso F., Autore G., Antiulcer effect of flavonoids. Role of endogenous PAF, Phytother. Res, 1994, 8, 179-181.

[27] Parmar N.S., Parmar S., Anti-ulcer potential of flavonoids. Ind. J. Physiol. Pharmacol., 1998, 42, 343-351.

[28] Martin M.J., Motilva V., Alarc L.C., Quercetin and naringenin, effects on ulcer formation and gastric secretion in rats. Phytother. Res., 1993, 7, 150-153.

[29] Kahraman A., Erkasap N., Koken T., Serteser M., Aktepe F., Erkasap S., The antioxidative and antihistaminic properties of quercetin in ethanol-induced gastric lesions. Toxicology, 2003, 183, 133-142.

[30] Mota K.S., Dias G.E., Pinto M.E., Luiz-Ferreira A., Souza-Brito A.R., Hiruma-Lima C.A., Barbosa-Filho J.M., Batista L.M., Flavonoids with gastroprotective activity. Molecules, 2009, 14, 979-1012.

Supplemental Material: The online version of this article offers supplementary material (https://doi.org/10.1515/chem-2018-0037). 